\title{
Corrigendum: Prevalence and Histopathologic Analyses of Mammary Tumors in Female Dogs in the Northeast of Algeria
}

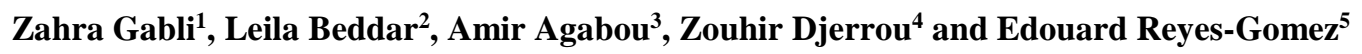 \\ ${ }^{1}$ Institut des Sciences Vétérinaires, Université des Frères Mentouri-Constantine 1, Constantine, Algérie \\ ${ }^{2}$ Service d'Histologie et d'Anatomie Pathologique, Centre Hospitalo-Universitaire Ben Badis, Constantine, Algérie \\ ${ }^{3}$ Laboratoire PADESCA, Institut des Sciences Vétérinaires, Université des Frères Mentouri-Constantine 1, Algérie \\ ${ }^{4}$ Département des Sciences de la Nature de la Vie, Faculté des Sciences, Université 20 Août 1955 Skikda, Algérie \\ ${ }^{5}$ Université Paris-Est, Ecole Nationale Vétérinaire d'Alfort, Unité d'Embryologie, d'Histologie et d'Anatomie pathologique, \\ BioPôle Alfort, Maisons-Alfort, France;
}

Correction to: OnLine Journal of Biological Sciences http://doi.org/10.3844/ojbsci.2017.166.177, published online 26 September 2017; updated 10 April 2018

The original version on this Article did not include Dr. Amir Agabou as a Co-Author.

In addition, the Author's Contribution section has been updated to the following.

Zahra Gabli: This work was carried out in collaboration between all authors. The first author assisted all the steps of this work: He designed the study, assisted sample collection, data analysis and manuscript preparation.

Leila Beddar: Supervised the study, coordinated the data-analysis and contributed to the writing of the manuscript.

Amir Agabou: Participated actively in data analyses and interpretation, writing the paper and critically revising it.

Zouhir Djerrou: Contributed in drafting the manuscript and reviewing it critically.

Edouard Reyes-Gomez: Performed histopathological findings, analyzed and interpreted the results, coordinated the data-analysis and contributed to the writing of the manuscript.

These errors have now been corrected in the HTML and PDF versions of the Article. http://doi.org/10.3844/ojbsci.2018.115 